Nasadyuk C. M.

\title{
CELL THERAPY IN GASTROENTEROLOGY
}

\section{ABSTRACT}

The article highlights the up-to-date literary data about the role of tissue and circulating stem cells in the processes of regeneration and carcinogenesis of gastric mucosa and intestine and development of liver and pancreatic fibrosis. The paper also presents the novel methods of treatment of common gastrointestinal diseases with the use of cell and gene technologies.

KEYWORDS: stem cells; regenerative therapy; gastrointestinal tract

Diseases of the gastrointestinal tract occupy a significant place in the structure of general morbidity in Ukraine and abroad, impairing the quality of life of young people and often become the cause of decreased working ability and disability $[1,11,21]$. Modern pharmacotherapy and surgical treatment of peptic ulcer disease, disorders of liver and pancreatic gland, Crohn's disease and ulcerative colitis in many cases do not provide the desired therapeutic effect $[1,10,21]$. Diseases of the gastrointestinal tract are characterized by chronicity, tendency to recurrence, development of functional insufficiency and often malignancies [1, 4, 32].

In recent years, considerable attention of scientists is directed to the investigation of biological characteristics of digestive tract stem cells: their involvement in the regeneration of the mucous layer of the stomach and intestines, liver, as well as in the processes of malignant transformation and metastasis [4, 20, 22, 29, 36]. Equally important is the subject of mobilization and possible involvement of circulating bone marrow stem cells in the regeneration and carcinogenesis of the digestive tract [26,33]. Simultaneously the approaches to the use of cell and gene technologies in the treatment of the digestive tract pathologies and immunobiological therapy based on the application of cytokines (interleukin 12/23, interleukin-6R, etc), monoclonal antibodies (especially to tumor necrosis factor-a), as well as personalized treatment using nanoparticles to transport drugs are being developed [8, 22, 24, 26].

In gastrointestinal diseases, restorative effect of stem cells introduced into the bloodstream or locally are explained by their paracrine effect stimulation of regenerative processes through the provision of numerous growth factors and the possibility to transdifferentiation [22, 35]. The therapeutic impact of mesenchymal stem cells in the treatment of liver fibrosis and pancreatic cancer, and autoimmune diseases of the digestive tract including Crohn's disease and ulcerative colitis, is supposed to be due to their prominent immunosuppressive effect [6, 16, 22, 33]. Mesenchymal stem cells also have been used in the treatment of "graftversus-host" disease in recipients of bone marrow, which mainly affects the mucous membranes of the digestive tract [25, 33].

Development of tissue engineering made possible endoscopic application of artificially grown tissue flaps to restore foci of the intestine affected by the pathological process [17].
It is believed that stem cell therapy can be used as an alternative treatment for chronic peptic ulcer [3]. Also cell therapy is considered to be the next generation of therapeutic interventions in the treatment of systemic inflammatory diseases of the colon, especially for patients with secondary resistance to anticytokine therapy [14, 22]. Today significant clinical experience of stem cells application in the treatment of liver failure and pancreatic disorders as well as genetically mediated diseases of the intestine, including celiac disease has been accumulated $[5,11,16,24,29]$.

\section{CELL THERAPY IN THE TREATMENT OF GASTRIC AND DUODENAL ULCERS}

Healing of the ulcerative defect is a complex and multistage process involving inflammation, cell proliferation, reepitalisation, angiogenesis and other mechanisms controlled by cytokines, including endothelial and platelet-derived growth factors, keratinocyte growth factor, transforming growth factor-beta, vasculoendothelial growth factor, action of angiopoietins etc. [35, 27, 28]. Also it was found that circulating progenitor cells, including bone marrow derived stem cells play a crucial role in the healing of the ulcer of the mucous membranes, regeneration of connective tissue, neovascularization [27]. Thus, local gene therapy using vasculoendothelial growth factor and Ang1 and/or SRF cDNAs were shown to accelerate significantly the healing of ulcers of the esophagus and stomach [28].

In experimental studies on the model of acetic acid-induced gastric lesions in rats, the use of autologous multipotent mesenchymal stromal bone marrow cells reduced the destructive phase of inflammation and accelerated ulcer healing. Bioregulatory activity of bone marrow stem cells, homing in the area of ulcers was observed within 30 days after their introduction [4].

Regenerative effect of bone marrow stem cells was demonstrated on a model of experimental gastric lesions in rats caused by ethanol [15]. For example, bone marrow stem cells of transgenic rats expressing green fluorescent protein were transplanted to experimental animals 30 days before the induction of gastric ulcers. After the end of the experiment labeled bone marrow stem cells were found both in the gastrointestinal 
epithelium and interstitial cells, and in rats with induced gastric ulcer number of labeled stem cells in tissues was significantly higher compared with animals without ulcers [15].

\section{CELL THERAPY IN THE TREATMENT OF ULCERATIVE COLITIS AND CROHN'S DISEASE}

Cell therapy of the inflammatory bowel disease includes two directions: immunosuppressive therapy followed by transplantation of hematopoietic stem cells and systemic or local application of mesenchymal cells [22]. The latter reduce the activity of autoimmune inflammation and exert regenerative effects $[6,7,18,22,33]$.

Uptodate research has also shown that patients with ulcerative colitis have reduced number of endothelial progenitor cells, and effectiveness of infusion of these cells in order to stimulate the regeneration of mucous ulcers is being explored [7].

In numerous preclinical and clinical studies efficacy of mesenchymal stem cells from bone marrow, adipose tissue, amniotic fluid, umbilical cord blood in the treatment of Crohn's disease and ulcerative colitis was shown $[7,18,33]$. The advantage of mesenchymal stem cells is the lack of immunogenicity, what allows more widespread allogeneic application of them [33].

Cell therapy of inflammatory bowel disease can reduce pain, diarrhea, signs of inflammation, bleeding and stimulates repair processes $[7,18,33]$. Mesenchymal stem cells increase the number of T-regulatory lymphocytes and reduce the amount of activated effector cells in the recipient [7]. At the same time regulatory effect of mesenchymal stem cells on the course of immune processes in the spleen and mesenteric lymph nodes was noted [18].

Today more than 200 clinical trials on the evaluation of therapeutic efficacy of mesenchymal stem cells are registered worldwide, 27 projects of which are devoted to the treatment of intestinal disorders [33]. According to the literary data, over 1,500 patients with inflammatory bowel disease were carried out systemic or local treatment using mesenchymal stem cells. Therefore, the 1 and 2 phases of clinical studies have confirmed the safety of cell therapy in the treatment of the colon disorders and its advantages over the use of fibrin glue in patients with fistulas [31, 33]. As mentioned above, cell therapy is particularly important for patients refractory to anticytokine drugs [14].

\section{CELL THERAPY IN THE TREATMENT OF LIVER CIRRHOSIS AND VIRAL HEPATITIS}

Today 3 therapeutic approaches to the correction of pathological conditions associated with liver failure are accepted worldwide. They are bioartificial extracorporeal liver, injection of hepatocytes suspensions that enhance regeneration of organ or perform metabolic functions and tissue engineering of the liver [29]. The scientists believe that introduction of alternative treatment based on the use of stem cells into clinical practice can provide effective treatment for many patients with liver failure $[16,19,29,34]$.

It was established that hepatocyte progenitor cells are present in the final bile ducts (canals of Hering) between the portal and hepatic lobules [16]. These cells are believed to be involved in liver regeneration, especially if the organ damage is significant and associated with the violation of proliferation of hepatocytes $[16,19]$. Hepatocyte progenitor cells are considered to be promising biological material to stimulate liver regeneration in chronic diseases. It is also known that hepatocyte progenitor cells may be involved in the development of pathological processes in the liver, in particular - fibrosis [16].

A recent study found that bone marrow cells are involved in liver regeneration [34, 37]. 3 populations of bone marrow stem cells: hematopoietic and mesenchymal stem cells and endothelial progenitor cells have practical value in the context of liver regeneration [34]. In preclinical studies bone marrow stem cells have been shown to contribute to the repair processes of liver through multiple mechanisms, including transdifferentiation into hepatocytes, paracrine stimulation of regeneration of hepatocytes, inhibition of activated star-shaped cells of the liver, increase of fibrinolytic activity of matrix metalloproteinases and neovascularization [34].

In mice on a model of liver fibrosis regenerative ability of stem cells of amniotic fluid was explored. Thus, 4 weeks after the treatment morphological analysis (area of fibrosis, hydroxyproline content, enzymatic activity) confirmed the effectiveness of cell therapy [23]. Also, experimental studies have shown that transplantation of stem cells of the pulp of teeth differentiated into hepatocytes in vitro, morphologically and functionally improved state of the liver in rats with acute liver failure and secondary biliary cirrhosis. In this study the scientists also reported that no risk of malignancy of application of cultured dental pulp stem cells was noted [12].

Efficiency of mesenchymal stem cells infusion in the treatment of liver cirrhosis was confirmed by a number of clinical studies [34, 37]. The improvement of clinical indices of the functional state of the liver in patients who underwent cell therapy with mesenchymal bone marrow stem cells was marked [34]. In patients with liver cirrhosis and hepatitis B the feasability, safety and efficacy of autologous hepatocytes cultured in vitro from bone marrow cells was shown. Thus, 12 patients with cirrhosis and posthepatitis portal hypertension, who were carried out splenectomy and periesophageal devascularization were divided into 2 groups. Group I (6 patients) within 7 days were injected into hepatic artery autologous hepatocytes derived in vitro from bone marrow cells, while the second group received saline and the same surgery as the first group. During the 2-year follow-up no side effects of stem cell therapy were reported and marked improvement of the functional state of the liver was noted compared with patients who were administered placebo [19].

1 year follow up in 30 patients with decompensated cirrhosis who underwent treatment with cord blood mesenchymal stem cells did not reveal any adverse effects of cell therapy and a significant improvement of the functional state of the liver was noted, increase of the content of albumin and a decrease in total bilirubin in serum compared with the control group of patients [37].

In Ukraine, Institute of Cell Therapy conducts clinical trials to evaluate the effectiveness of the use of cord blood stem cells in the treatment of viral hepatitis and liver cirrhosis.

\section{CELL THERAPY IN THE TREATMENT \\ OF PANCREATIC NECROSIS}

Therapeutic strategies associated with transplantation of stem cells into pancreas for many years have been aimed at restoring of insulin production by beta cells of the Lanherhans islets. However, in recent years, cell technologies are increasingly used in the treatment of acute and chronic pancreatitis [2, 11, 24].

Since it is known that NF-kB signaling pathway plays an important role in the development of chronic pancreatitis and pancreatic fibrosis the effectiveness of transplantation of mesenchymal stem cells with inhibited NF-kB gene was studied in experimental research. Thus, in the model of chronic pancreatitis in rats it was shown that inhibition of NF-kB signaling pathway reduced the level of proinflammatory cytokines and activated apoptosis of star-shaped cells of the pancreas, which play a key role in the development of fibrosis and progression of pancreatic insufficiency [24].

In rats with acute pancreatitis caused by $3 \%$ sodium tauroholate intravenous administration of umbilical cord blood mesenchymal stem cells in a dose of $1.10^{7}$ cells $/ \mathrm{kg}$ resulted in the decrease of amylase activity in serum on the $1^{\text {st }}, 3^{\text {rd }}$ and $5^{\text {th }}$ day after transplantation and decrease of lipase activity on the $3^{\text {rd }}$ and $5^{\text {th }}$ day. Also in the group of animals treated with umbilical cord blood mesenchymal stem cells decrease of edema and inflammatory cell infiltration of pancreas as well as reduction of hemorrhages and degree of necrosis were seen [11].

Clinical studies have shown that intravenous administration of cord blood reduced the extent of intoxication and anemia in patients with necrotizing pancreatitis, normalized glucose and protein profile of blood, reduced symptoms of cytolytic syndrome, namely a dynamic decrease 
of the activity of aspartate aminotransferase, alanine aminotransferase, gamma-glutamyltranspeptidase, lactate dehydrogenase was observed [2].

In 2012, the Ministry of Health of Ukraine approved treatment for acute pancreatitis using cord blood stem cells and umbilical cord tissue, developed by the Institute of Cell Therapy.

\section{CELL THERAPY IN THE TREATMENT OF GENETICALLY MEDI- ATED DISEASES OF THE DIGESTIVE TRACT}

Stem cell transplantation is considered as a new treatment of genetically mediated disorders of the intestine [22]. The literary data gives evidence of two clinical cases of successful transplantation of hematopoietic stem cells after myeloablation in the treatment of celiac disease. After treatment the introduction of gluten-containing diet caused no clinical, serological and histological manifestations of the disease during the 5-year follow-up period [29].

It is known that hereditary deficiency of the interleukin-10 and its receptor leads to severe colitis that is resistant to standard treatments. The effectiveness of transplantation of hematopoietic stem cells was observed in patients with colitis on the background of interleukin-10 deficiency [16].

\section{CELL THERAPY IN THE TREATMIENT OF DIGESTIVE TRACT MALIGNANCIES}

Investigation of the molecular mechanisms of tissue regeneration involving circulating and tissue progenitor cells sheds new light on the processes of carcinogenesis and creates prerequisite for the development of new treatments for the digestive tract malignancies and prevention of metastasis [9].

Experimental studies have shown that bone marrow mesenchymal stem cells in every $4^{\text {th }}$ case are involved in the development of neoplastic processes in the stomach, but in the other cases epithelial-mesenchymal transformation of tissues occurs $[4,22]$. It was also demonstrated that
Helicobacter pylori infection may also lead to the development of gastric cancer via induction of chronic inflammation in the mucous membrane with the involvment of bone marrow stem cells [4, 22]. Chronic infection and inflammation lead to disruption of regeneration and differentiation of both local epithelial stem cells and cells derived from the bone marrow. This causes the emergence of metaplasia and dysplasia, and additional mutations which may lead to the development of cancer stem cells and appearance of malignant tumors [4]. We also know that cancer stem cells or circulating tumor cells play an important role in tumor invasion and resistance to anticancer therapy [20]. There is evidence that bone marrow stem cells may be involved in the development of carcinomas of the upper gastrointestinal tract - the esophagus and stomach [32]. Therefore, to date, inhibition of gastric cancer stem cells is considered as one of the mechanisms of anticancer therapy [20,36].

It is believed that the use of bone marrow stem cells can improve the safety and efficacy of chemotherapy, radiotherapy and surgery in the treatment of hepatocellular carcinoma [30].

In experimental studies in mice with engrafted human malignant tumors of stomach and pancreas in the abdominal cavity the efficacy of the application of myeloid cells, obtained from induced pluripotent stem cells was shown, what was expressed in significant inhibition of cancerogenesis [26].

Mesenchymal stem cells modificated to secrete HMGB1proteinsantagonists possess huge antitumor potential. The efficacy of the application of these cells was observed in studies on mice with engrafted colon cancer [13].

Thus, due to recent literary reports introduction of cell technologies into gastroenterology significantly expands the possibilities of pharmacotherapy and surgery of the gastrointestinal disorders and creates opportunities to the improvement of efficacy of treatment, prevention of progression and complications.

\section{REFERENCES}

1. Denisova TP, Shuldyakov VA, Tyultyaeva $L A$, et al. Monitoring rasprostranennosti zabolevanij vnutrennih organov na primere patologii pishhevaritel'noj sistemy [Monitoring the incidence of diseases of the internal organs on the example of the pathology of the digestive system]. Saratovskij nauchno-medicinskij zhurnal Saratov Journal of Medical Scientific. 2011; 4:772-776.

2. Kebkalo $A B$, Salyutin RV, Lobintseva GS. Biohimichni zmini v plazmi krovi hvorih na nekrotichnij pankreatit pri transplantaciï stovburovih klitin kordovoï krovi [Biochemical changes in the blood plasma of patients with necrotizing pancreatitis with stem cells transplantation of cord blood]. Medicina s'ogodni i zavtra. Medicine Today and Tomorrow. 2011;1-2:50-51.

3. Askarov MB. Multipotent mesenchymal stromal cells from autologous bone marrow accelerate regeneration of refractory gastric ulcers. Eksp. Klin. Gastroenterol. 2008; 4:52-54.

4. Bessède E, Dubus P, Mégraud F, et al. Helicobacter pylori infection and stem cells at the origin of gastric cancer. Oncogene. 2014. http://www.ncbi.nlm.nih.gov/ pubmed/25043305.

5. Ciccocioppo R, Bernardo ME, Russo ML, et al. Allogeneic hematopoietic stem cell transplantation may restore gluten tolerance in patients with celiac disease. J. Pediatr. Gastroenterol. Nutr. 2013; 56(4):422-427.

6. De Miguel MP, Fuentes-Julián S, Blázquez-Martínez A, et al. Immunosuppressive properties of mesenchymal stem cells: advances and applications. Curr. Mol. Med. 2012; 12(5):574-591.

7. Deng $X$, Szabo $S$, Chen $L$, et al. New cell therapy using bone marrow-derived stem cells/endothelial progenitor cells to accelerate neovascularization in healing of experimental ulcerative colitis. Curr. Pharm. Des. 2011;17(16):1643-1651.

8. Dhama K, Chakraborty S, Mahima MY, et al. Novel and emerging therapies safeguarding health of humans and their companion animals: a review. Pak. J. Biol. Sci. 2013; 16(3):101-111.

9. Hoffmann W. Regeneration of the gastric mucosa and its glands from stem cells. Curr. Med. Chem. 2008; 15(29):3133-3144.

10. Hommes DW, Duijvestein $M$, Zelinkova Z, et al. Long-term follow-up of autologous hematopoietic stem cell transplantation for severe refractory Crohn's disease. J. Crohns Colitis. 2011; 5(6):543-549.

11. Meng Hong-Bo, Gong Jian, Zhou Bo, et al. Therapeutic effect of human umbilical cord-derived mesenchymal stem cells in rat severe acute pancreatitis. Int. J. Clin. Exp. Pathol. 2013; 6(12): 2703-2712.

12. Ishkitiev N, Yaegaki $K$, Imai $T$, et al. Novel management of acute or secondary biliary liver conditions using hepatically-differentiated human dental pulp cells. Tissue Eng. Part A. 2014. http://www.ncbi.nlm.nih.gov/pubmed/25234861

13. Kikuchi $\mathrm{H}$, Yagi $\mathrm{H}$, Hasegawa $\mathrm{H}$, et al. Therapeutic potential of transgenic mesenchymal stem cells engineered to mediate anti-high mobility group box 1 activity: targeting of colon cancer. J. Surg. Res. 2014; 190(1):134-143.

14. Kniazev OV, Parfenov Al, Ruchkina IN, et al. New possibilities for overcoming the secondary inefficiency of anti-cytokine therapy in patients with inflammatory bowel diseases. Ter. Arkh. 2013; 85(2):57-60.

15. Komori M, Tsuji S, Tsuji $M$, et al. Efficiency of bone marrow-derived cells in regeneration of the stomach after induction of ethanol-induced ulcers in rats. J. Gastroenterol. 2005; 40(6):591-599. 
16. Lanthier N, Rubbia-Brandt L, Spahr L. Liver progenitor cells and therapeutic potential of stem cells in human chronic liver diseases. Acta Gastroenterol Belg. 2013; 76(1):3-9.

17. Leggett CL, Gorospe EC, Lutzke L, et al. A new era: endoscopic tissue transplantation. Curr. Opin. Gastroenterol. 2013; 29(5): 495-500.

18. Li L, Liu S, Xu Y, et al. Human umbilical cord-derived mesenchymal stem cells down regulate inflammatory responses by shifting the Treg/Th17 profile in experimental colitis. Pharmacology. 2013; 92(5): 257-64.

19. Liao X, Cheng An JY, Zhou QJ, et al. Therapeutic effect of autologous bone marrow-derived liver stem cells transplantation in hepatitis B virus-induced liver cirrhosis. Hepatogastroenterology. 2013; 60(123):406-409.

20. Liu G, Neumeister $M$, Reichensperger J, et al. Therapeutic potential of human adipose stem cells in a cancer stem cell-like gastric cancer cell model. Int. J. Oncol. 2013; 43(4):1301-1309.

21. Nasadyuk C, Sklyarov A. Thymohexin exhibits cytoprotective effect in experimental gastric lesions in rats both through the inhibition of inducible nitric oxide synthase and reduction of oxidative mucosal damage. Regul.Pept. 2013; 180:50-57.

22. Nasadyuk CM. Stem Cell Therapy In The Treatment Of Inflammatory Bowel Disease. Gastroenterology\&Hepatology: Open Access. 2014; 1(1):00006.

23. Peng SY, Chou CJ, Cheng PJ, et al. Therapeutic potential of amniotic-fluid-derived stem cells on liver fibrosis model in mice. Taiwan J. Obstet. Gynecol. 2014; 53(2):151-157.

24. Qin T, Liu CJ, Zhang HW, et al. Effect of the lkBa mutant gene delivery to mesenchymal stem cells on rat chronic pancreatitis. Genet Mol Res. 2014; 13(1):371-385.

25. Resnick IB, Barkats C, Shapira MY, et al. Treatment of severe steroid resistant acute GVHD with mesenchymal stromal cells (MSC). Am. J. Blood Res. 2013; 19(3):225-238.

26. Senju S, Koba C, Haruta M, et al. Application of iPS cell-derived macrophages to cancer therapy. Oncoimmunology. $2014 ; \mathbf{1 ( 3 ) : e 2 7 9 2 7 .}$

27. Tarnawski AS, Ahluwalia A. Molecular mechanisms of epithelial regeneration and neovascularization during healing of gastric and esophageal ulcers. Curr. Med. Chem. 2012; 19(1):16-27.

28. Tarnawski AS. Cellular and molecular mechanisms of gastrointestinal ulcer healing. Dig Dis Sci. 2005; 50(1):S24-33.

29. Vacanti JP, Kulig KM. Liver cell therapy and tissue engineering for transplantation. Semin. Pediatr. Surg. 2014; 23(3):150-155.

30. Vainshtein JM, Kabarriti R, Mehta KJ, et al. Bone marrow-derived stromal cell therapy in cirrhosis: clinical evidence, cellular mechanisms, and implications for the treatment of hepatocellular carcinoma. Int. J. Radiat. Oncol. Biol. Phys. 2014; 15(89):786-803.

31. van Deen W K, Oikonomopoulos A, Hommes DW. Stem cell therapy in inflammatory bowel disease: which, when and how? Curr. Opin. Gastroenterol. 2013; 29(4):384390.

32. Varon $C$, Dubus $P$, Mazurie $F$, et al. Helicobacter pylori infection recruits bone marrow-derived cells that participate in gastric preneoplasia in mice. Gastroenterology. 2012; 142(2):281-291.

33. Voswinkel J, Francois S, Gorin NC, et al. Gastro-intestinal autoimmunity: preclinical experiences and successful therapy of fistulizing bowel diseases and gut Graft versus host disease by mesenchymal stromal cells. Immunol. Res. 2013; 56(2-3):241-248.

34. Wan Z, You S, Rong Y, et al. CD34+ hematopoietic stem cells mobilization, paralleled with multiple cytokines elevated in patients with HBV-related acute-on-chronic liver failure. Dig Dis Sci. 2013; 58(2):448-457.

35. Watanabe S, Arimura Y, Nagaishi K, et al. Conditioned mesenchymal stem cells produce pleiotropic gut trophic factors. J. Gastroenterol. 2014 ; 49(2):270-282.

36. Yu L, Yang L, An W, et al. Anticancer bioactive peptide-3 inhibits human gastric cancer growth by suppressing gastric cancer stem cells. J. Cell Biochem. 2014; 115(4):697-711.

37. Zhang Z, Lin H, Shi $M$, et al. Human umbilical cord mesenchymal stem cells improve liver function and ascites in decompensated liver cirrhosis patients. J. Gastroenterol. Hepatol. 2012; 27(2):112-120.

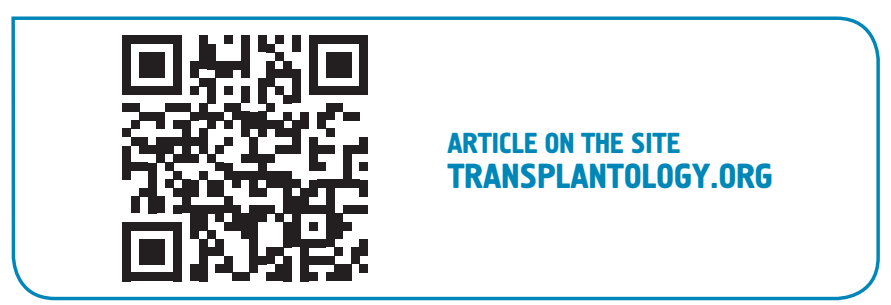

The author indicates no potential conflicts of interest.

Accepted: February 27, 2015 